\title{
Heparin-Mimicking Polymer Modified Polyethersulfone Membranes - A Mini Review
}

\author{
Tao Xiang ${ }^{\mathrm{a}}$, Chong Cheng ${ }^{\mathrm{a}}$ and Changsheng Zhao ${ }^{\mathrm{a}, \mathrm{b},{ }^{*}}$ \\ ${ }^{a}$ College of Polymer Science and Engineering, State Key Laboratory of Polymer Materials Engineering, \\ Sichuan University, Chengdu 610065, China \\ ${ }^{b}$ National Engineering Research Center for Biomaterials, Sichuan University, Chengdu 610064, China
}

\begin{abstract}
Recent studies on the modification of polyethersulfone (PES) membranes using heparin-mimicking polymers are reviewed. The general conception of heparin-mimicking polymersis defined as the syntheticpolymers (including the biopolymer derivates and synthetic sulfated artificial polymers) with similar biologically functionalities as heparin, such as the anticoagulant, growth factor binding, and also disease mediation. In the review, heparin-mimicking polymers is briefly reviewed; then heparin-mimicking polymer modified PES membranes, including blended, coated, and grafted membranes are discussed respectively.
\end{abstract}

Keywords: Heparin-mimicking, polyethersulfone, blood compatibility, blending, coating.

\section{INTRODUCTION}

Polyethersulfone (PES) and PES-based membranes have been extensively applied in separation fields, due to their outstanding hydrolytic, thermal, and oxidative stabilities, as well as good mechanical property. One of the main application fields is in biomedical field, such as medical devices and artificial organs used for blood purification (plasma collection, plasmapheresis, hemofiltration and hemodialysis) [1-4]. However, proteins will rapidly adsorb onto the PES membrane surfaces after contacting with blood, leading to further undesirable results, such as platelet adhesion, platelet activation, aggregation and thrombus formation. As a result, hemocompatibility of the membrane is not very good, and injection of anticoagulant iscrucial during the clinical application [5]. Thus, modification of PES membranes used for biomedical applications is needed.

Pinnau et al. [6] summarized the most universally practical modification methods for membranes, including chemical treatment (pyrolysis, crosslinking, fluorination), surface coating, solvent treatment, and annealing with heat treatment. Van der Bruggen et al. [7] reviewed the chemical and physicochemical methods for the modification of PSF/PES nanofiltration (NF) membranes to improve the hydrophilicity. Chemical or physical modifications after the fabrication of membrane provide more hydrophilic surfaces. Such

*Address correspondence to this author at College of Polymer Science and Engineering, State Key Laboratory of Polymer Materials Engineering, Sichuan University, Chengdu 610065, China; Tel: +86-28-85400453; Fax: +86-2885405402; E-mail: zhaochsh70@163.com, zhaochsh70@scu.edu.cn modification processes are (1) physical pre-adsorption of hydrophilic compounds onto the surfaces; (2) plasma treatment to introduce various functional groups onto the surfaces; and (3) grafting polymerization of hydrophilic monomers attached to the surfaces. Most recently, we reviewed the modification methods of PES membranes [8]. Two types of membranes, including hollow fiber and flat-sheet membrane types were discussed respectively. The modifications are aimed to improve the antifouling property, blood compatibility and other specific functions.

In this review, recent studies on the modification of polymeric membranes using heparin-mimicking polymer to increase the membrane blood compatibility are discussed. Firstly, heparin-mimicking polymers are briefly reviewed; then heparin-mimicking polymer modified membranes, including blended, coated, and grafted membranes, are discussed respectively.

\section{HEPARIN-MIMICKING POLYMERS}

Heparin, composed of repeating disaccharide units of uronic acid and glucosamine, is the first glycosaminoglycans applied in medicine. The hydroxyl and amino groups of the glucosamine units are partially sulfated. It is a highly sulfated glycosaminoglycan, and has been widely used as an injectable anticoagulant.

Heparin-mimicking polymers can be defined as the syntheticpolymers (including the biopolymer derivates and synthetic sulfated artificial polymers) with similar biologically functionalities as heparin, such as the anticoagulant, growth factor binding, and also disease mediation. The heparin-mimicking polymers are ionic polymers owningionic functional groups such as 
carboxylic acid, sulfamide, and sulfate, and it is believed that the presence of the groups [9$11]$ contributed to the anticoagulant activity of heparin as shown in Figure 1.

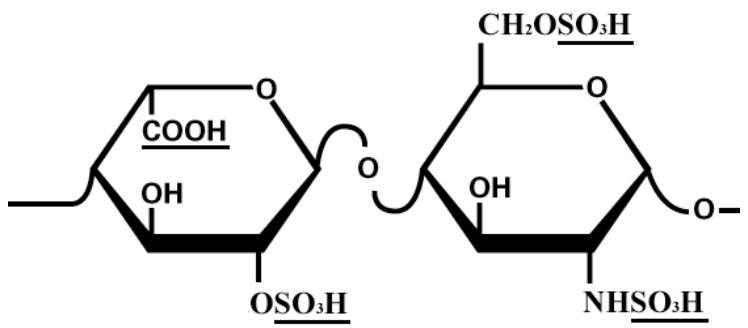

Figure 1: Molecular structure of heparin.

\subsection{Natural Biomacromolecule Derived Heparin- Like Polymers}

The first study on heparin-like polymers is based on the natural biomacromolecules. RGTA11, was deemed efficiently to preserve the heparin-binding growth factors FGF2 against trypsin digestion, which was a dextran derivative containing carboxymethyl, carboxymethyl benzylamide, and carboxymethyl benzylamide sulfonate groups, thus could mimic heparin [12]. The RGTA11 also presented antiinflammatory and tissue repair activities mediated by growth factor protection, which would be benefit to digestive ulcer treatment [13]. Then, it was found that beta-cyclodextrin sulfates could also be used to mimic heparin as inhibitor on angiogenesis [14]

Since heparin can be regarded as the sulfonation of the hydroxyl and amino groups of glucosamine units, the sulfonation of other polysaccharides such as the laminarin might yield very potent new anticoagulants and express heparin-like biological activities [15]. Heparin-like oligosaccharides also showed heparin biological activities [16, 17]. Thioglycosides was also utilized to synthesize the heparin-like oligosaccharides with well-defined reactivity. The proposed one-pot synthesis method of uronic acids through the selective oxidation at C-6 after the assembly of the oligosaccharides is highly efficient [18].

Hansen et al. reported an efficient method to synthesizea structurally defined heparin-like dodecasaccharide [19].The $\mathrm{H}-3$ radiolabelling was utilized to provide the first example of this kind of agent for monitoring in vivo stability and in vivo tissue distribution of a structurally defined andbiologically active heparin-like dodecasaccharide. Furthermore, the group also confirmed that the heparin-like oligosaccharides, such as the octa-, deca-, and dodecasaccharides [20].The investigation of the activity in vitro for these compoundsagainst $\operatorname{VEGF(165)}$ and FGF2suggested that the octa- and decasaccharides were more effective to target FGF2 induced effects, where the cell migration was affected more obvious than the proliferation. The relationships of the structure and activity exemplified significant effect of the 6-Osulfation in regulating the activity for angiogenic growth factors.

To mimic the anticoagulation of heparin, Pereira et al. designed sulfated fucans, which was composed of oligosaccharide repeating units with sulfation and also was one of the most widely studied sulfated polysaccharides of non-mammalian origin [21]. The comparison results of anticoagulant activities of the sulfated fucans from echinoderms and brown algae indicated that different structural features determined not only the anticoagulant potency but also the mechanism by which they exerted this activity. Andrade et al. had isolated another natural heparin-like compound from crab. From the analysis of nuclear magnetic resonance and enzymatic, it was found that the compound was rich in disulfated disaccharides, owning large quantities of the 2-O-sulfated-beta-Dglucuronic acid units [22]. This heparin-like compound showed negligible in vitro anticoagulant activity and low bleeding potency, thus it was a promising alternativeto develop therapeutic agents which were structuredriven, heparin based andwith fewer undesirable effects.

Apart from the bio-isolated heparin-like polymers, a series of synthesized biopolymer based heparin-like derivatives had been intensively reported. Yang et al. reported the 6-carboxylchitin derivatives with different sulfate group and $\mathrm{N}$-acetyl group contents [23]. The in vitro anticoagulant activity results indicated that all the 6-carboxylchitin derivatives had prolonged activated partial thromboplastin times (APTTs). It confirmed that the anticoagulant activity for the heparin-like polymers strongly depended on their chemical structures. Recently, our group synthesized a sulfated chitosan derivative by sulfating the phthaloylated chitosan [24], and the novel derivative was dissolved in many organic solvents, as shown in Figure 2.

Lia et al. prepared the sulfated hyaluronic acid (SHA) to modify the electrically conductive polypyrrole (PPY) film. The plasma recalcification time (PRT) for the SHA modified films were obviously prolonged compared tothe HA modified films. The platelet adhesion was also reduced [25]. Moreover, the 

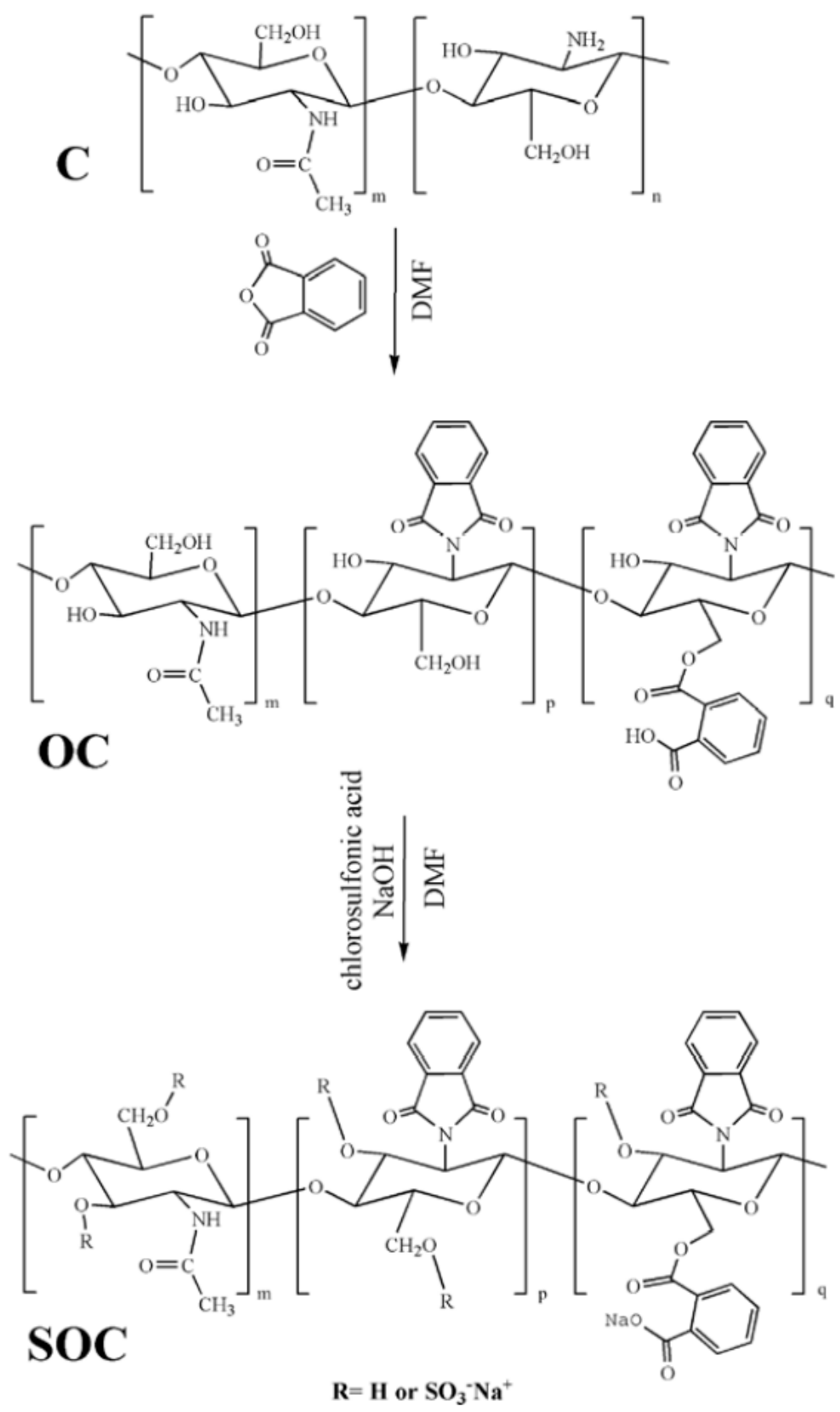

Figure 2: Synthesis of sulfated derivative of chitosan (SOC).

heparin-like polymers also showed anti-inflammatory properties by reducing the activity of the MMP-9 secreted by the human activated leukocytes and also reducing the flux of the inflammatory cells to injury site [26].

In general, many kinds of natural biomacromolecules, especially for polysaccharides, can be used to prepare heparin-mimicking polymers. However, few of the studies concerned membranes. Also, it is difficult to modify membranes using the heparin-mimicking polymers by blending method, since the polymers are water-soluble, while most of membrane matrixes are water insoluble. Coating and grafting methods to modify membranes using the heparin-mimicking polymers may be good choices.

\subsection{Synthetic Polymer Derived Heparin-Like Polymers}

Thrombus formation on blood-contacting artificial surfaces is a major problem. A series of antithrombogenic heparinized surfaces had been obtained either by heparin binding, or by grafting biomacromolecules based heparin-like polymers. However, the application of these approaches is limited 
by their inherit drawbacks of high cost and complex synthesis process [27]. Thus, the development of ideal antithrombogenic polymersis a primary objective in the blood-contacting fields of artificial hearts, cardiovascular prostheses, hemodialysis, and other devices. The synthesized sulfated polymers become the emerging star in the application of blood-contacting fields due to their low-cost, facile, and controllable synthetic processes.

To prepare synthetic heparin-like polymer, the mostly widely used method is the sulfonation of the present and/or synthetic polymers. Jang et al. [28] synthesized novel copolymers of sulfonated PEG acrylate (PEG-SO $\left.{ }_{3} \mathrm{~A} / \mathrm{OA}\right)$ and polyethylene glycol (PEG), and used as the blending and/or coating materials for biomedical applications. The copolymer modified surfaces showed decreased plasma adsorption level and d anti-coagulation propertydue to the increased reorientation characteristics and hydrophilic properties of the PEG/PEG-SO ${ }_{3} \mathrm{~A}$ chains in water phase.
Ran et al. [29] synthesized apolymer via RAFT polymerization, and a heparin-like structure was obtained after the sufonatation using the sulfonating agent of concentrated sulfuric, as shown in Figure 3. The clotting time of the heparin-like polymer (HLSM) was longer than that of the pureplasma using a small amount of the HLSM, and the plasmabecame anticoagulate when $2 \mathrm{mg} / 100 \mu \mathrm{L}$ of heparin-like polymer was used.

Many kinds of polymers such as PES, polysulfone, polystyrene, and so on, can be prepared into heparinlike polymers by the sulfonation, for which the sulfonic acid groups can replace the hydrogen atoms at the ortho position on the aromatic rings [30, 31]. The sulfonating agents used in the sulfonation were sulfur trioxide $\left(\mathrm{SO}_{3}\right)$ [32, 33], trimethyl silylchlorosulfate $\left(\left(\mathrm{CH}_{3}\right)_{3} \mathrm{SiSO}_{3} \mathrm{Cl}\right)$ [32, 34-38], sulfuricacid $\left(\mathrm{H}_{2} \mathrm{SO} 4\right)[30$, $39,40]$, and chlorosulfonic acid $\left(\mathrm{ClSO}_{3} \mathrm{H}\right)$ [41-46].

Another method to prepare heparin-like polymers is a direct synthesis approach using sulfonic and/or carboxyl group contained monomers, and the most

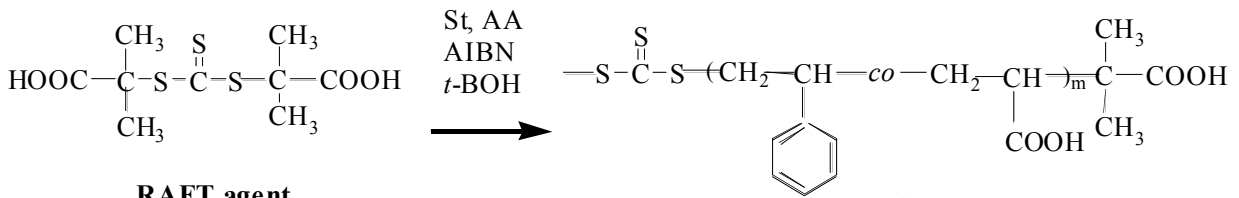

RAFT agent
P(St-co-AA)

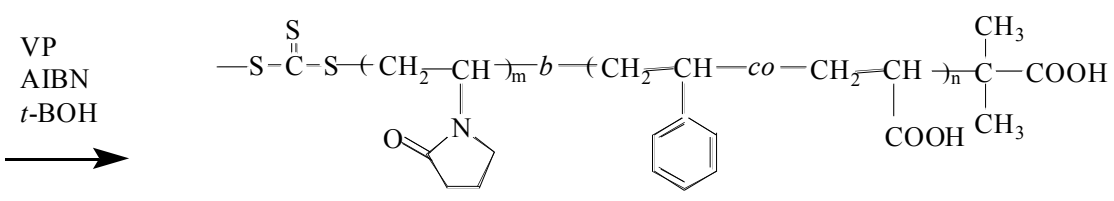

P(St-co-AA)-b-PVP-b-P(St-co-AA)

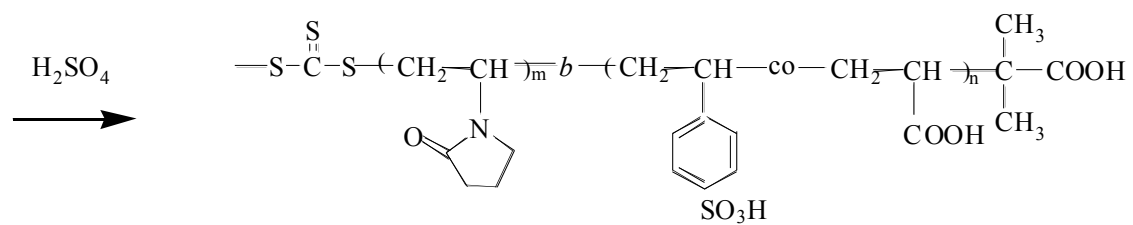

P(SSt-co-AA)-b-PVP-b-P(SSt-co-AA)

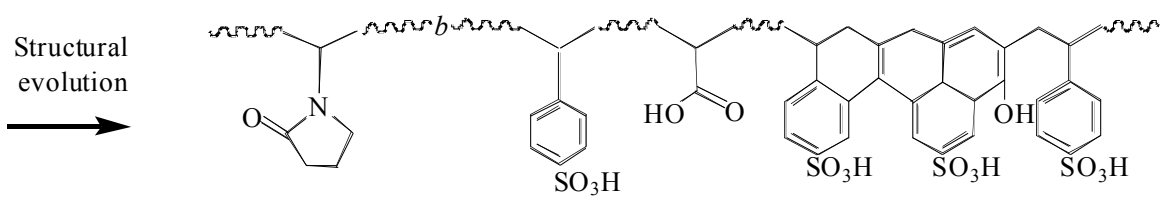

Heparin-like structure macromolecule (HLSM)

Figure 3: Synthesis of the heparin-like structure macromolecule. 
widely used monomer is sodium-4-styrenesulfonate (SS). Sangaj et al. [47] found that the synthetic poly(sodium-4-styrenesulfonate) (PSS) could mimic the effect of heparin on the myogenic differentiation for $\mathrm{C} 2 \mathrm{C} 12$ cell. The differentiation of $\mathrm{C} 2 \mathrm{C} 12$ were increased with the exogenous supplementation in a dose-dependent manner, however a nonmonotonic dependence with the PSS concentration was showed for the formation of the multinucleated myotubes. It was found that the binding capacity of the PSS to bFGF was comparable to heparin by molecular docking calculations and through native PAGE. Maynard group [48] established that the heparin-like copolymer, poly(polyethylene glycol methylether methacrylate-cosodium 4-styrenesulfonate) (p(PEGMA-co-SS)) could stabilize bFGF by covalent conjugation. The bioactivity of the bFGF conjugate for the copolymer was retained after the synthesis, which is much better than the earlier developed PEG conjugation. The conjugate was stable to various therapeutically and environmentally stressors, such as harsh, mild and heat acidic conditions, storage and proteolytic degradationdifferent from the native bFGF.

In a recent report [49], two different methacrylic derivatives of anti-angiogenic monomers, 2-acrylamido2-methylpropane sulfonic acid (AMPS) and 5-amino-2naphthalenesulfonic acid (MANSA) were copolymerized with a hydrophobic monomer (butyl acrylate, BA) or a hydrophilic monomer (vinyl pyrrolidone, VP), then synthetic heparin-like

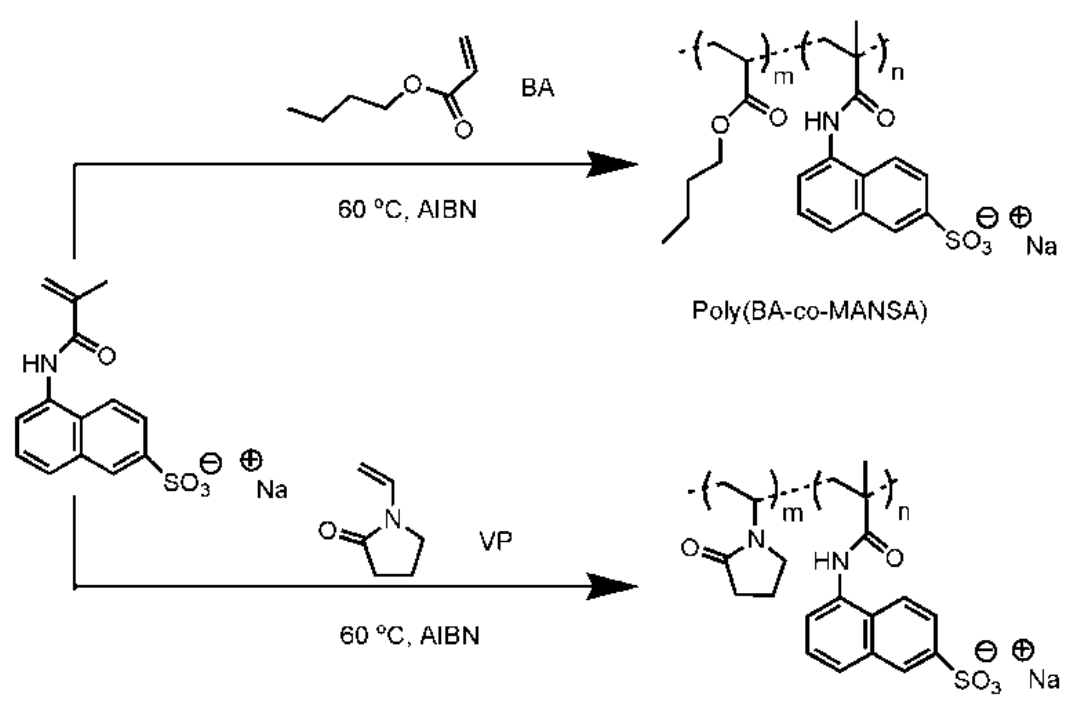

Poly(VP-Co-MANSA)

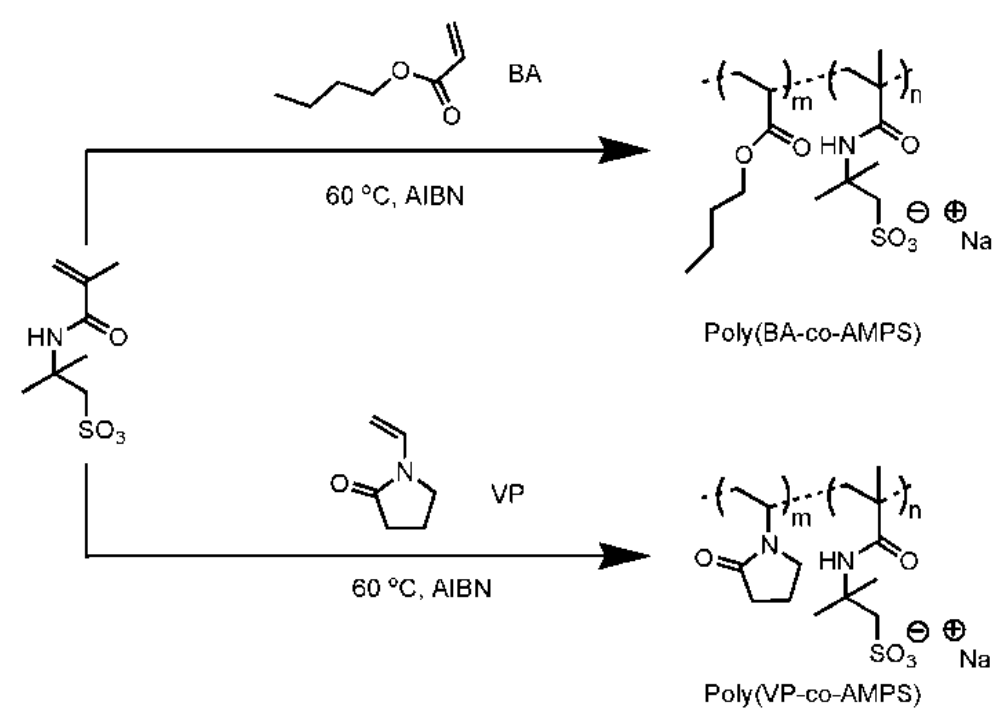

Figure 4: Synthesis of the different heparin-like macromolecules. 
macromolecules were prepared, as shown in Figure 4. The macromolecules were also found to act as antiangiogenic polymeric drugs.

Wang et al. [50] successfully prepared a heparinlike polymer of PES (HLPES) by the polycondensation and carboxylation reactions. The HLPES exhibited excellent heparin-like activity, and the clotting times were about $44.3 \%$ of that for heparin. Uchman et al. [51] synthesized a heparin-like amphiphilicterpolymer of poly((sulfamate-carboxylate)isoprene)-co-polystyreneco-poly(ethylene oxide) (PISC-co-PS-co-PEO) to prepare heparin-like multicompartment micelles, for which the core was consisted of discrete PISC and PS domains, and the shell was consisted of PEO. Recently, we grafted PSS onto GO through free radical polymerization [52]. The APTT was dramatically prolonged with the concentration of the PSS-g-GO from $0.5 \mu \mathrm{g} / 100 \mu \mathrm{L}$ to $20 \mu \mathrm{g} / 100 \mu \mathrm{L}$, which was resulted from the increment of the sulfonic and carboxyl groups in PSS-g-GO. The TT also prolonged to some extent.

In a word, most of the heparin-like polymers are synthesized for specific applications, such as modification of micelles and membranes. The blood compatibility for the membranes increased, which will be discussed in the following sections in detail.

\section{HEPARIN-LIKE POLYMER BLENDED MEMBRANES}

Methods for the modification of PES membrane usuallyinclude coating, physical blending and surface grafting. Herein, modifications of polymeric membranes using heparin-like polymers are reviewed; of course, the above methods can also be used to modify other polymeric membranes.Blending is the simplest, but most widely applied method for the modification of membranes, though sometimes the results might be not very well. Thus, heparin-like polymer blended PES membranes are discussed firstly.

Heparin-like polymers derived from natural biomacromolecules had been intensively studied as mentioned above. However, due to the water-soluble and organic solvent non-soluble properties of the polymers, few studies had been reported on the modification of PES membranes using the polymers. Most recently, our group [24] synthesized a sulfated chitosan derivative with good solubility in many common solvents. Then modified PES membranes could be prepared by blending the sulfated chitosan derivative with PES. The modified membranes possessed decreased protein adsorbed amounts and suppressed platelet adhesion (as shown in Figure 5). Moreover, the APTT of the modified membranes was

Table 1: Heparin-Like Polymers Used to Modify Membranes

\begin{tabular}{|c|c|c|c|}
\hline Modification methods & Functional polymers & Possible applications & References \\
\hline \multirow[t]{10}{*}{ blending } & sulfated chitosan derivative & plasma separation & [24] \\
\hline & citric acid grafted polyurethane & plasma separation & [53] \\
\hline & $P($ St-co-AA)-b-PVP-b-P(St-co-AA) & hemodialysis & [54] \\
\hline & su fated $P($ St-co-AA)-b-PVP-b-P(St-co-AA) & hemodialysis & [29] \\
\hline & MPEG-P(SSNa-Co-MMA) & hemofiltration & [56] \\
\hline & sulfonated PES & plasma separation & [57-60] \\
\hline & $P(A N-A A-V P)$ & hemofiltration & [58] \\
\hline & carboxylic PES & hemofiltration & [59] \\
\hline & $P(A A-N a S S-V P)$ & plasma separation & [61] \\
\hline & $P($ HEMA-AA) & plasma separation & [62] \\
\hline \multirow[t]{4}{*}{ Coating } & P(NaSS-AA), dopamine & hemofiltration & [63] \\
\hline & $\mathrm{CHI} / \mathrm{PSS}$ multilayer & protein separation & [64] \\
\hline & PSS / protonated PAH; PSS/ PDADMAC & hemofiltration & [65] \\
\hline & Ag NPs/PEI/PSS & antibacterial & [66] \\
\hline \multirow[t]{3}{*}{ Grafting } & HEMA, NVP; AAG, AA; AMPS, SPMA & hemofiltration & {$[67,68]$} \\
\hline & zwitterionic copolymers & plasma separation & [70] \\
\hline & P(SBMA-NaSS) & plasma separation & [71] \\
\hline
\end{tabular}



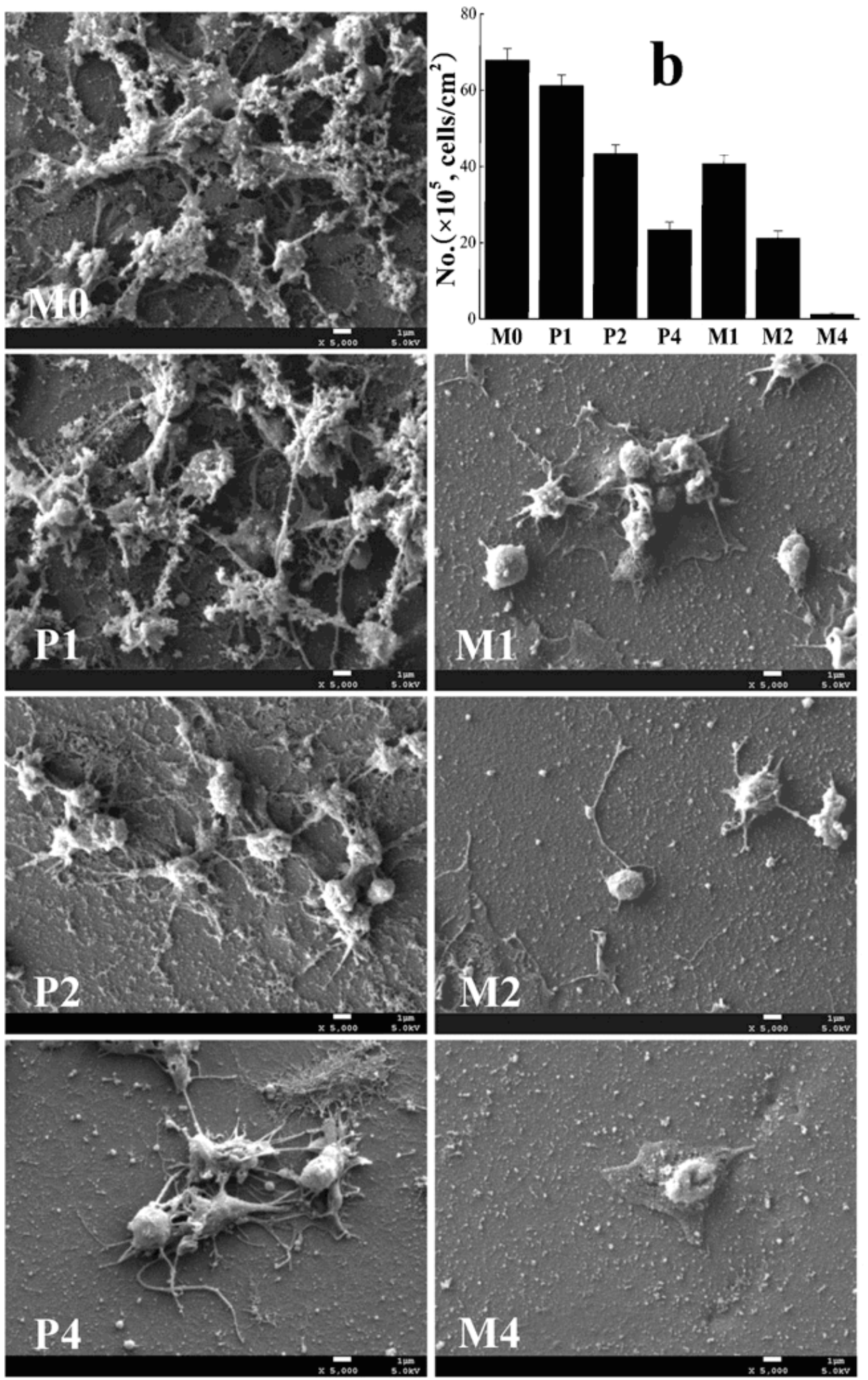

Figure 5: Typical SEM images of the platelets adhered on themembranes; magnification: $5000 \times$. (b) Number of the adherent platelets on themembranes estimated from the SEM pictures. Note: The membranes with the PES/OC (as control samples) ratios of $16 / 1,16 / 2$, and 16/4 (wt.\%) are termed P1, P2, and P4, respectively; The prepared membranes with the PES/SOC ratios of $16 / 0,16 / 1,16 / 2$, and 16/4 (wt.\%) are termed M0, M1, M2, andM4, respectively.

increased about $60 \%$ compared to the pristine PES membrane. The study provided a method to modify polymeric membranes using heparin-like polymers.
Citric acid is a weak organic acid, and consists of 3 carboxyl (R-COOH) groups. Though, it has no sulfonic groups, it is a widely used anticoagulant due to the carboxyl groups. Li et al. [53] synthesized citric acid 
grafted polyurethane bya two-step polymerization. The blending solution of the synthesized polymer and PES could be prepared into PES modified membranes, which revealed decreased protein adsorption amounts and suppressed platelet adhesion. The APTT, PRT, prothrombin time (PT), and the whole blood clotting time (WBCT) of the modified membranes were significantly prolonged due to the binding ability of calcium ions in blood. Using acrylic acid as a monomer, Nie et al. [54] synthesized a novel triblock copolymer, poly(styrene-co-acrylic acid)-b-poly(vinyl pyrrolidone)b-poly(styrene-co-acrylic acid) (P(St-co-AA)-b-PVP-b$\mathrm{P}(\mathrm{St}-\mathrm{co}-\mathrm{AA})$ ) via RAFT polymerization, which was then used for the modification of PES membrane by blending. The APTT for the membrane was prolonged; while the thrombin-antithrombin III (TAT) generation and platelet activation were decreased. Since there are no sulfonic groups in the polymers, the hemocompatibility for the modified membrane was not obviously improved.

To mimic the structure of heparin, a HLSM was synthesized by RAFT polymerization as mentioned above [29]. The HLSM/PES blended membranes were prepared by using a phase separation technique. The anticoagulant ability of the membranes may be improved due to the binding capacity of the anionic groups $\left(-\mathrm{SO}_{3} \mathrm{H}\right.$ and-COOH$)$ on the membrane surfaces The results illustrated that the anticoagulant properties of the modified membranes were significantly enhanced, and the HLSM modified biomaterials has potential to be applied in blood purification including bioartificial liver supports and hemodialysis. Different heparin-like polymers, including poly(sulfonated styrene-co-acrylic acid-co-methyl methacrylate) (P(SSco-AA-co-MMA)), poly(acrylic acid-co-methyl methacrylate) (P(AA-co-MMA)), and poly(sulfonated styrene-co-methyl methacrylate) (P(SS-co-MMA))were synthesized and then utilized to modify PES membranes [55]. The hemocompatibility of the membranes was also compared. The results indicated that the membrane using the heparin-like polymer with appropriate proportions of MMA, AA and SS showed better performance, and one possible anticoagulant mechanism of the modified membrane is summarized as in Figure 6.

Besides RAFT technique, atom transfer radical polymerization (ATRP) can also be used for the synthesis of heparin-like polymers. He et al. [56] synthesized a random terpolymer of MPEG-P(SSNaco-MMA) by ATRP for the first time, which was then used as an additive for the modification of PES membranes by blending method. The results illustrated that the hydrophilicity was increased for the modified membranes, and the antifouling property of the modified membrane was improved compared to the pristine PES membrane. In addition, the modified membranes also revealed suppressed platelet adhesion and prolonged APTTs.

As mentioned above, the heparin-like polymers should contain both sulfonic groups and carboxyl groups to improve the blood compatibility of PES membranes. In the studies, it was also found that the miscibility of the PES matrix and heparin-like polymers was not very well, and phase separation occurred during the membrane preparation using the blending method.

To improve the miscibility of heparin-like polymers and PES matrix, several other polymers were

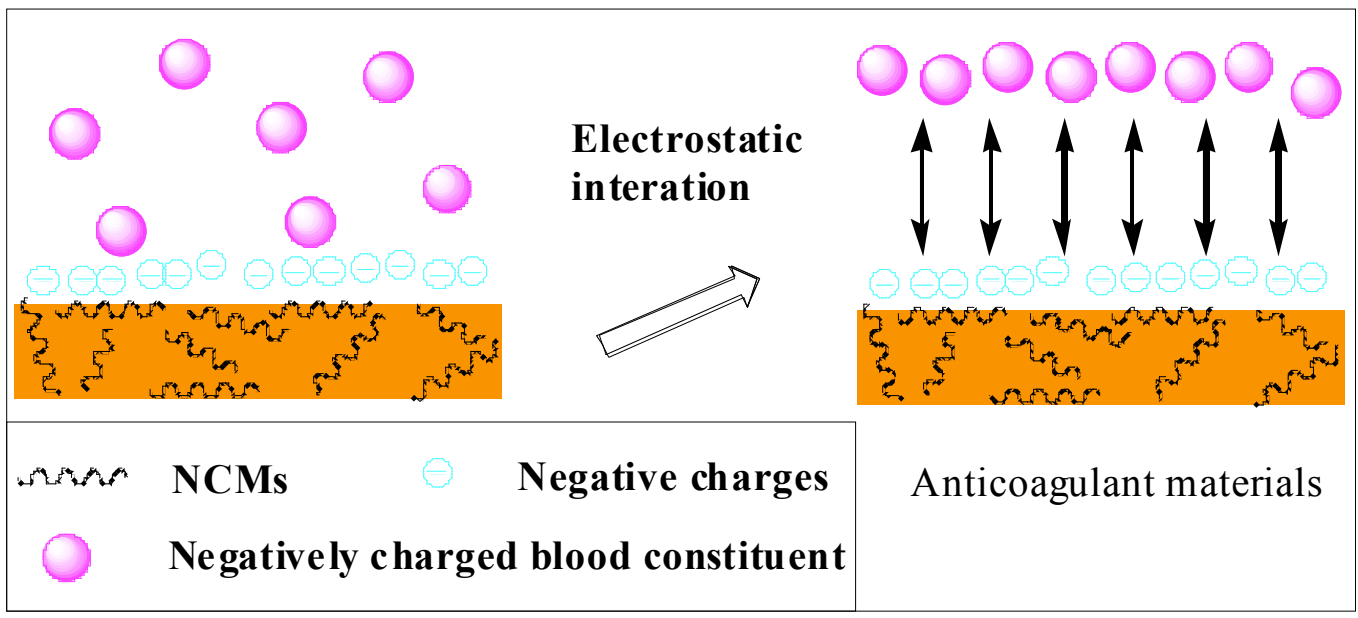

Figure 6: Schematic illustration of the interaction between the negatively charged blood constituents and the anticoagulant biomaterial surface. 
synthesized. Wang et al. [57] synthesized a sulfonated PES (SPES) by using an electrophilic substitution reaction, and then PES/SPES blended membranes were prepared. The PES/SPES blended membrane could effectively decrease BSA adsorption and prolong the blood clotting time compared tothe pristine PES membrane, thereby improving hemocompatibility. To further improve the hemocompatibility of PES membrane and construct heparin-like membrane surface, poly (acrylonitrile-co-acrylic acid-co-vinyl pyrrolidone) (P(AN-AA-VP)) and SPES, for which providing the $-\mathrm{COOH}$ and $-\mathrm{SO}_{3} \mathrm{H}$, respectively, were blendedin PES membrane [58]. The P(AA-AN-VP) was prepared by a free radical polymerization. The modified membrane revealed lower protein adsorption amount and suppressed platelet adhesion. In addition, the modified membrane showed significantly decreased TAT, complement activation on C3a and C5a levels, and percentage platelets positive for CD62p expression compared to the pristine PES membrane. Due to the similar negatively charged groups as heparin, the modified membranes could effectively prolong the APTT. Furthermore, the modified membranes revealed good cytocompatibility. This study may be the first time to construct heparin-like membrane surface, and the surface modification with heparin-like structure has potential to improve the blood compatibility of biomaterials.

To further increase the miscibility, carboxylic PES (CPES) was used instead of $\mathrm{P}(\mathrm{AA}-\mathrm{AN}-\mathrm{VP})$ to provide carboxylic acid groups, then modified membranes with heparin-like structure were prepared by physically blending PES, CPES and SPES at rational ratios [59]. Since the SPES and CPES had the same backbone as $P E S$, which conferred them good miscibility with PES.SPES can also be synthesized via a feasible way, in which sulfonic groups was introduced onto the amino-substituted PES [60]. The modified membranes could be fabricated by blending PES and the obtain SPES at any ratios. The SEM images illustrated that the structure of the modified PES membranes changed obviously after the modification. The modified membranes showed increased APTT and PRT, and also showed suppressed blood platelet adhesion.

Recently, heparin-like PES (HLPES) was synthesized as mentioned above by the polycondensation and carboxylation reactions [50]. The modified PES/HLPES membranes could be prepared by blending the HLPES and PES at any ratios, due to the similar structure of backbone. The hydrophilicity was significantly improved for the modified membranes, while the microscopic structure was also changed. The PES/HLPES membranes showed obviously decreased leukocytes activation on CD11b levels, complement activation on C3a and C5a levels, and platelet activation on PF-4 level compared to the pure PES membrane. The enhanced hemocompatibility of the modified membranes might be due to the negatively charged groups $\left(-\mathrm{SO}_{3} \mathrm{Na}\right.$ and $\left.-\mathrm{COONa}\right)$.

Most recently, a special blending method, termed in situ cross-linked polymerization/copolymerization was provided for the blood-compatible modification of PES membranes [61]. The monomers of AA, NaSS, and VP with the same weight ratios were used in the facile modification. The APTTs of the modified membranes were obviously increased. Furthermore, due to the heparin-like structure, theAA and NaSS modified membranes revealed significantly improved anticoagulant property. In addition, many other functional polymers owning outstanding $\mathrm{pH}$-sensitivity and $\mathrm{pH}$-reversibility, anticoagulant property, antifouling property, and antibacterial property could be synthesized by the in situ cross-linked polymerization/copolymerization. Themethod of in situ cross-linked polymerization/copolymerization opens a route for the functionalization of polymers, which leads to significant progress for the applications of polymeric materials.

Then, Qin et al. [62] developed a highly efficient, convenient and universal protocol for blood-compatible modification of PES membranes via in situ cross-linked copolymerization of 2-hydroxyethl methacrylate (HEMA) and acrylic acid (AA) in PES solutions, as shown in Figure 7. The modified membranes showed improved hydrophilicity, good blood anticoagulant and antifouling properties after introducing HEMA and AA. Meanwhile, the modified membranes perform low contact activation and complement activation when they come in contact with blood. The effect of the HEMA/AA ratios on the blood compatibility is also investigated to identify the different roles played by PHEMA and PAA in the modification; the PHEMA could more effectively enhance the antifouling property, while the PAA could more effectively improve the anticoagulant property.

\section{HEPARIN-LIKE POLYMER COATED MEMBRANES}

Surface coating is an approach to modify material surface with a coating of selective thin filmlayer (TFL). By surface coating, porous UF/MF membranes could 


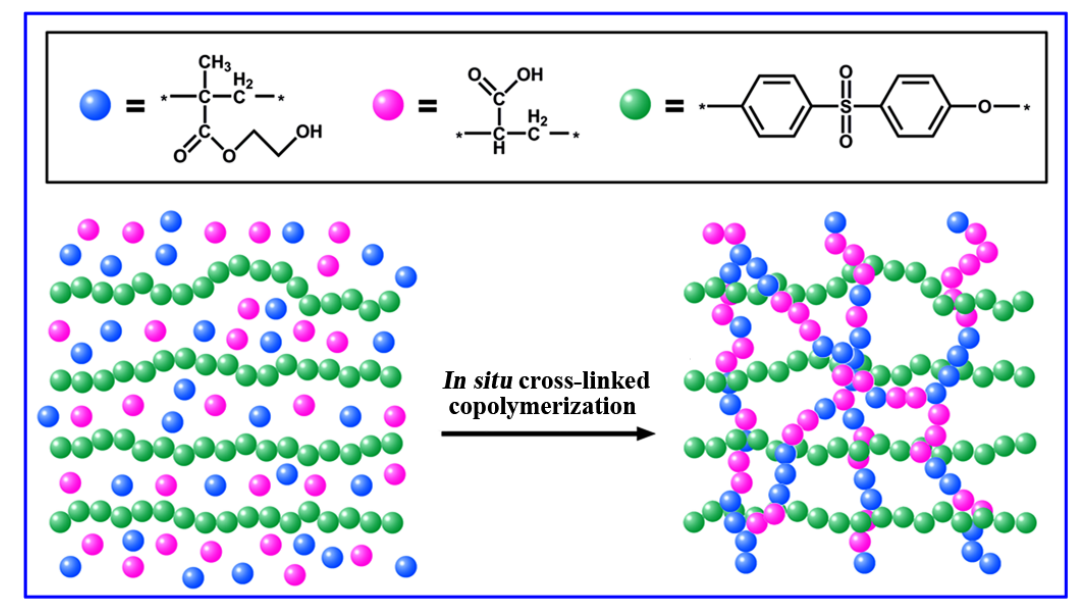

Figure 7: In situ cross-linked copolymerization of AA and HEMA.

be prepared into nanofiltration membrane. However, directly surface coating heparin-like polymers onto PES membranes is not a good choice, since the polymers can be easily washed away due to the water solubility; thus no study was reported on directly surface coating heparin-like polymers onto PES membranes.
Most recently, our group [63] reported a facile and green approach to prepare modified PES membranes with significant blood compatibility and cytocompatibility by multifunctional mussel-inspired coating, as shown in Figure 8. Heparin and a highly sulfonated linear heparin-like polymer (poly(sodium 4-vinylbenzenesul-

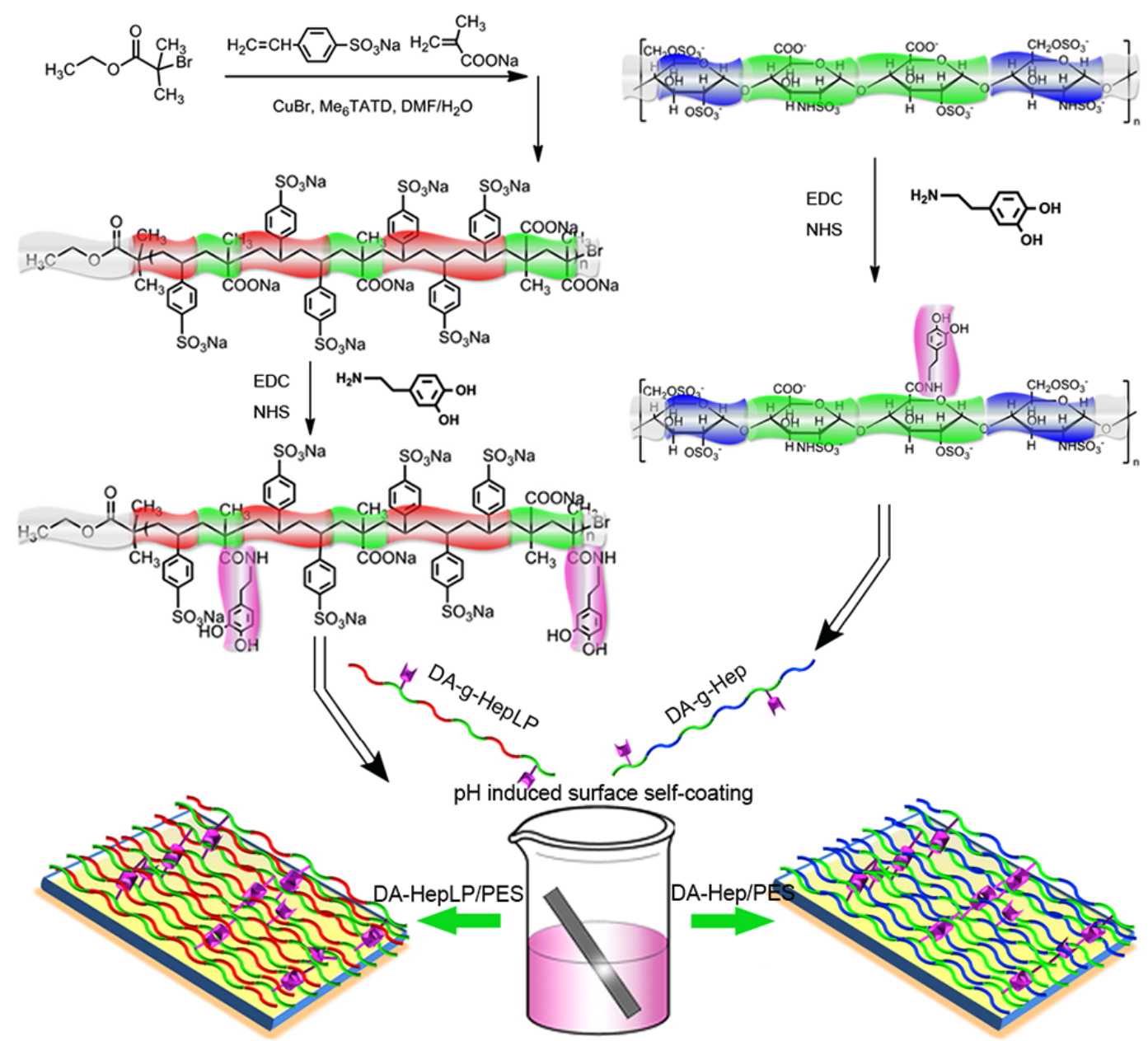

Figure 8: Schematic illustrations for the preparation of HepLP, DA-g-Hep, DA-g-HeLPp, DA-Hep/PES and DA-HepLP/PES. 
fonate)-co-poly(sodium methacrylate), HepLP) are chosen as the coating, respectively. Firstly, dopamine (DA) is grafted on the backbone of heparin or HepLP using the carbodiimide chemistry method. Then, the DA grafted DA-g-Hep and DA-g-HepLP were used as the coatings to modify the PES membranes. The coated membranes revealed increased electro negativity and hydrophilicity, reduced plasma protein adsorption, and suppressed platelet adhesion compared with those of the pure PES membrane. The cell morphology and MTT illustrated that the heparinmimicking PES membranes had superior performance in morphology differentiation and endothelial cell proliferation. Furthermore, the good anticoagulation suggested that the biological activity of the DA-g-Hep (or DA-g-HepLP) coating was realized or maintained after being immobilized. Thus, the heparin-mimicking PES membranes can be widely used in many biomedical applications such as hemodialysis and tissue cultures.

To enhance the water flux and selectivity of PES membrane, a novel coating of chitosan $(\mathrm{CHI})$ polystyrene sulfonate (PSS) multilayers was deposited. The modified membranes can be applied in protein separations under ultrafiltration conditions [64]. A significant change in the protein transport behavior through the multilayers was observed, and depended on the deposited layer numbers and the solution $\mathrm{pH}$ values. For a 9-bilayer CHI/PSS multilayer modified membrane, the transport studies revealed $95 \%$ rejection of BSA. The ovalbumin permeability was also enhanced. The individual transport studies of lysozyme and ovalbumin exhibited that the egg white proteins might be separated using the multilayer system.

Polymeric UF membranes could be converted into $\mathrm{NF}$ membranes by layer-by-layer (LBL) deposition of cationicandanionic polyelectrolytes. PSS /protonated
$\mathrm{PAH}$ and PSS/ poly(diallyldimethyl- ammonium chloride) (PDADMAC)could be deposited onto PES UF membrane [65] as shown in Figure 9. The membrane MWCO was reduced. The pure water flux of the PSS/PAH coated membrane was increased; while the chloride/sulfate selectivity of the PSS/PDADMAC coated membrane was increased.

Xia et al. [66] prepared modified PES membranes with 3D multifunctional nanolayers, which was deposited by LBL self-assembly of heparin-like polymers and nanogels. Ag nanoparticle embedded nanogels were prepared and assembled onto the membrane surfaces via electrostatic interaction to integrate long-term antibacterial activity. The nanogel coated membranes were further deposited with heparin-like polymers to gain heparin-like surfaces. The membranes revealed increased hydrophilicity, reduced protein adsorption, prolonged clotting time, and suppressed platelet adhesion compared to the pure PES membrane. The cell observations demonstrated that the pristine membrane, nanogel assembled membrane, and heparin-mimicking membrane showed different performances in endothelial cell proliferation and adhesion. The results of antibacterial study showed that the modified membranes exhibited significant inhibition capability for Staphlococcus aureus and Escherichia coli. Thus, the surface coassembly of nanogels and heparin-like polymers conferred the modified membranes with integrated blood compatibility, cell proliferation and antibacterial properties for multi-applications, as shown in Figure 10.

\section{HEPARIN-LIKE POLYMER GRAFTED MEMBRANES}

It is difficult to directly graft heparin-like polymers onto PES membranes. However, the functional groups (sulfonic and carboxyl groups) can be grafted onto PES

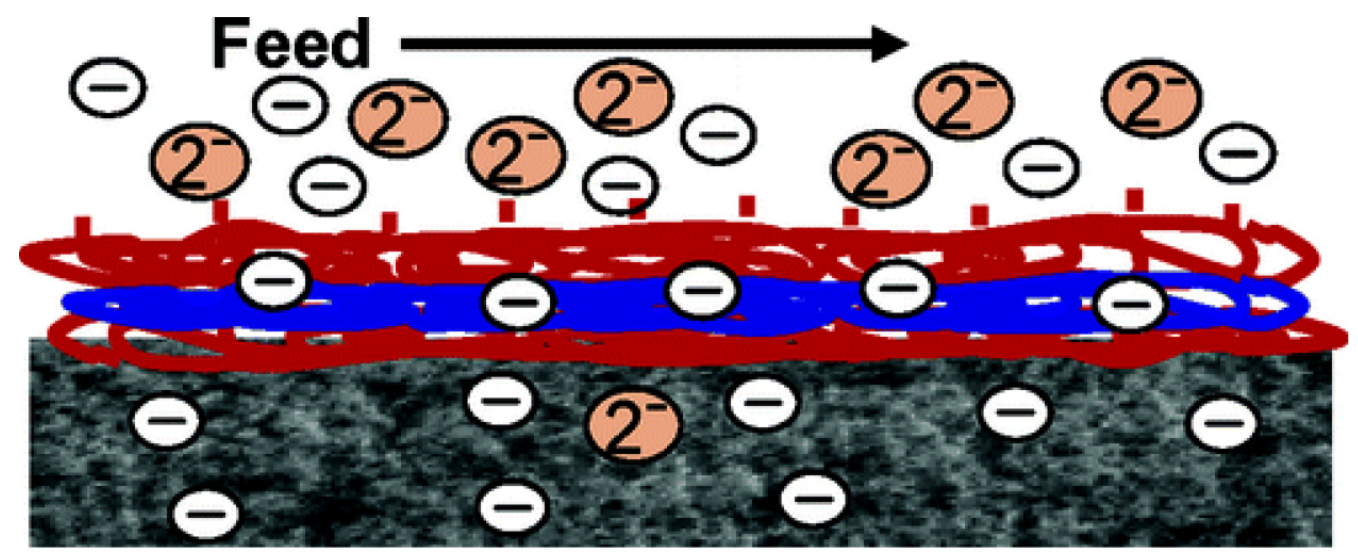

Figure 9: Layer-by-layer deposition of polyelectrolytes onto polymeric membrane. 


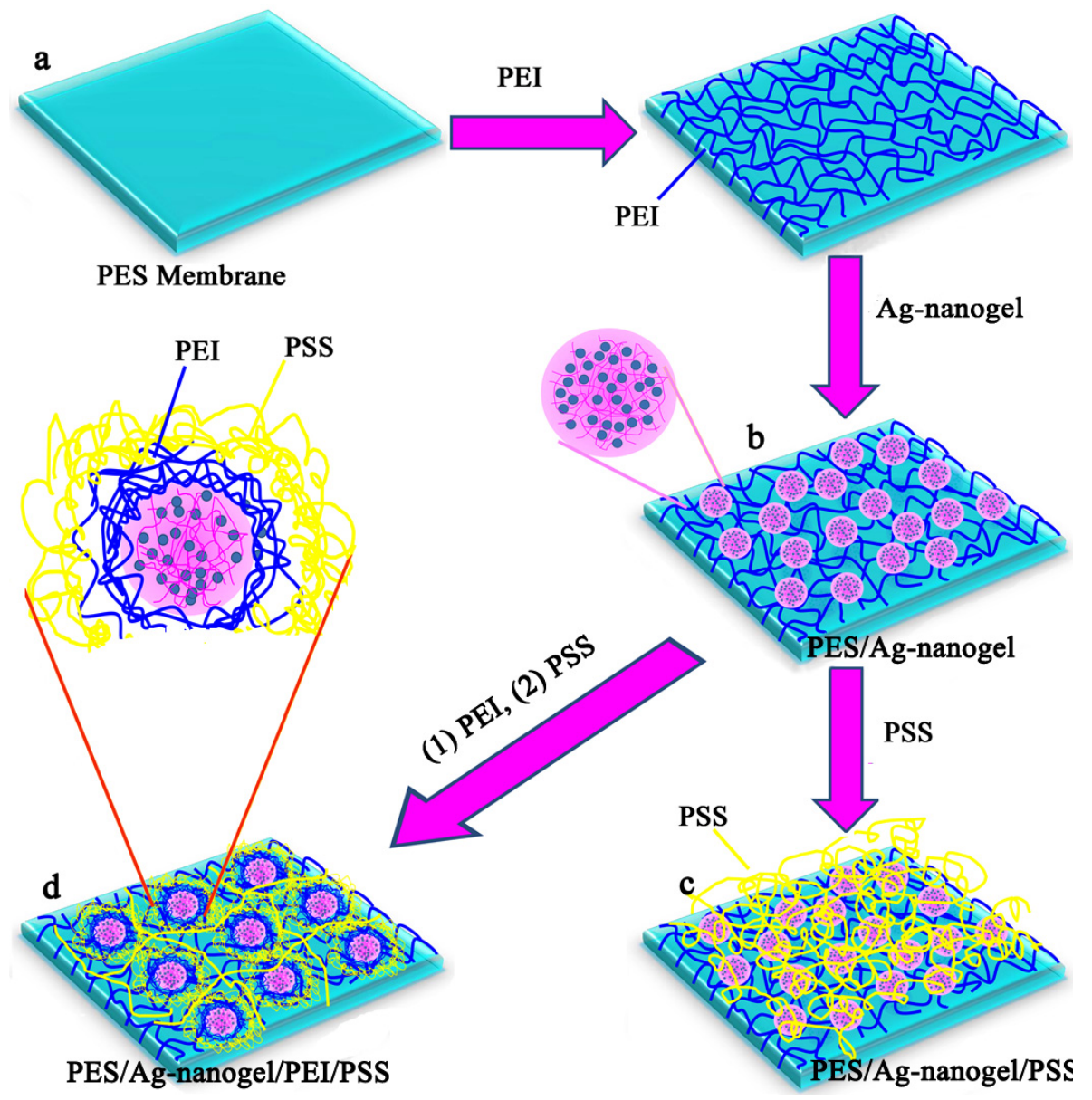

Figure 10: The fabrication processes for the 3D nanogel deposited membranes by surface engineered LBL assembly. (a) pristine PES membrane, (b) PES/Ag-nanogel, (c) PES/Ag-nanogel/PSS, and (d) PES/Ag-nanogel/PEI/PSS.

membrane surfaces. Taniguchi and Belfort $[67,68]$ studied the effect of different monomers on the performances of the modified membranes, and six different monomers, including 2 neutral (HEMA, NVP), 2 weak (carboxylic) acids (AAG, AA), and 2 strong (sulfonic) acids (AMPS, SPMA), were selected. Though the surface wettability of all the grafted polymers modified membranes were enhanced compared with that of the pristine PES membranes, the effect of the grafted polymers on filtration performance was various. Using the smaller pore-size PES membranes (50 kDa) for grafting, the membranes modified by NVP, AMPS and $A A$ showed excellent performance (such as high protein solution flux, high protein retention, as well as low irreversible fouling). For larger pore-size membranes (70 and $100 \mathrm{kDa}$ ), however, the PES-grAMPS and PES-gr-AA membranes showed reasonably high BSA rejection ratios and protein solution fluxes with excellent cleaning ability (with projected high longterm performance) compared to the pure membranes. In addition, the weak acid AA modified membranes were able to reduce irreversible fouling to zero, compared to other strongly hydrophilic monomers including HEMA and AAG, which increased irreversible fouling relative to the unmodified membrane [68].

Surface photochemical technique is an attractive method owing several advantages. Low temperature and mild reaction conditions migh tbe applied. In addition, high selectivity is possible by choosing monomers or the reactive groups and the respective excitation wavelength; and it is easily incorporated into the end stages of a manufacturing process [69].

Xiang et al. [70] synthesized two kinds of zwitterionic copolymers bearing azide andalkynylgroups by ATRP and subsequent reactions, namely azide-poly(sulfobetaine methacrylate) (azidePSBMA) and alkynyl-poly(sulfobetaine methacrylate) (alkynyl-PSBMA), which weredirectly used to modify azido-functionalized polysulfone $\left(\mathrm{PSf}-\mathrm{N}_{3}\right)$ membrane through click chemistry-enabled LBL assembly, as shown in Figure 11. The alkynyl-citric acid might also be grated onto the outermost layer of the membrane. The grafted multilayers were resistant to protein 


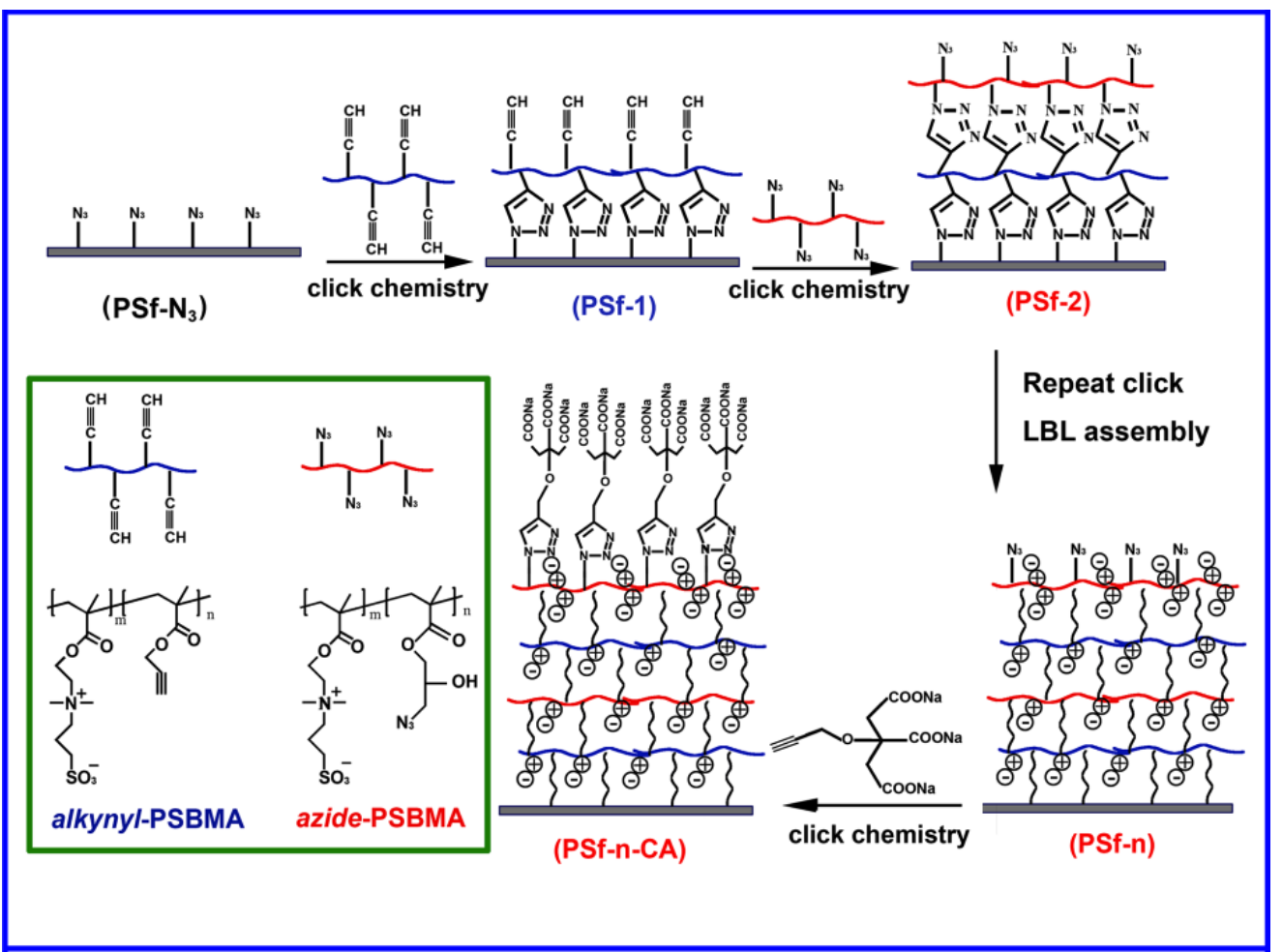

Figure 11: Scheme illustration for the preparation of zwitterionic polymer and citric acid deposited PSf membrane by click chemistry-enabled LBL assembly.

adsorption and platelet adhesion, and could prolong clotting times indicating the blood compatibility was improved. Moreover, the membrane showed further improved anticoagulant property after the outermost of the zwitterionic multilayer was deposited with alkynylcitric acid. The study provides a method to graft heparin-like polymers and other functional polymers onto membranes with reactive groups.

\section{CONCLUDING REMARKS AND FUTURE PERSPECTIVE}

Heparin-like polymers have been intensively studied; however, most of the studies focus on mimicking the heparin structure, i.e., the functional carboxyl and sulfonic groups, few of them pay attention on the heparin conformation. The anticoagulant property of heparin is caused by not only the functional groups but also its special conformation. Synthetic heparin-mimicking polymers have advantages such as low cost, facile, and controllable synthetic processes; natural biomacromolecules derived heparin-like polymers may show better anticoagulant property, and the polymers may be developed to instead of heparin using in clinic. In addition, the mechanism of the anticoagulant property for heparin-like polymers should be fully studied, which will guide the molecular design and characterization of heparin-like polymers.
Heparin-like polymers can be utilized to modify PES membranes via blending, coating, and grafting approaches. Blending method is the simplest, most widely used approach to modify PES membranes, and can be easily used for large-scale and in practice production. However, the elution of the polymers should be noted. Though surface coating heparin-like polymers onto PES substrate shows very good results of anticoagulant property, the stability of the coated polymers is very important. Few studies focus on grafting method, the emerging new methods such as RAFT and ATRP, may open the route on grafting heparin-like polymers onto membrane surfaces.

\section{ACKNOWLEDGEMENT}

This work was financially sponsored by the National Natural Science Foundation of China (No. 51225303). We should also thank our laboratory members for their contribution on the studies of heparin-like polymer modified PES membranes.

\section{REFERENCES}

[1] Zhao CS, Liu T, Liu ZB, Cheng LP, Huang J. An evaluation of a polyethersulfone hollow fiber plasma separator by animal experiment. Artif Organs 2001; 25: 60-3.

[2] Tullis RH, Duffin RP, Zech M, Ambrus JL. Affinity hemodialysis for antiviral therapy. I. Removal of HIV-1 from 
cell culture supernatants, plasma, and blood. Ther Apher 2002; 6: 213-20.

http://dx.doi.org/10.1046/j.1526-0968.2002.00407.x

[3] Samtleben W, Dengler C, Reinhardt B, Nothdurft A, Lemke $H-D$. Comparison of the new polyethersulfone high-flux membrane DIAPES $®$ HF800 with conventional high-flux membranes during on-line haemodiafiltration. Nephrol Dial Transpl 2003; 18: 2382-6. http://dx.doi.org/10.1093/ndt/gfg410

[4] Werner C, Jacobasch H-J, Reichelt G. Surface characterization of hemodialysis membranes based on streaming potential measurements. J Biomater Sci, Polym Ed 1996; 7: 61-76. http://dx.doi.org/10.1163/156856295X00832

[5] Liu ZB, Deng XP, Wang M, Chen JX, Zhang AM, Gu ZW, et al. BSA-modified polyethersulfone membrane: preparation, characterization and biocompatibility. J Biomater Sci, Polym Ed 2009; 20: 377-97.

http://dx.doi.org/10.1163/156856209X412227

[6] Pinnau I, Freeman BD. Formation and modification of polymeric membranes: overview: ACS Symposium Series 2000. 1-22 p.

[7] Van der Bruggen B. Chemical modification of polyethersulfone nanofiltration membranes: a review. J Appl Polym Sci 2009; 114: 630-42. http://dx.doi.org/10.1002/app.30578

[8] Zhao CS, Xue JM, Ran F, Sun SD. Modification of polyethersulfone membranes-A review of methods. Prog Mater Sci 2013; 58: 76-150.

http://dx.doi.org/10.1016/j.pmatsci.2012.07.002

[9] Tamada Y, Murata M, Hayashi T, Goto K. Anticoagulant mechanism of sulfonated polyisoprenes. Biomaterials 2002; 23: $1375-82$

http://dx.doi.org/10.1016/S0142-9612(01)00258-7

[10] Tamada Y, Murata M, Makino K, Yoshida Y, Yoshida T, Hayashi T. Anticoagulant effects of sulphonated polyisoprenes. Biomaterials 1998; 19: 745-50. http://dx.doi.org/10.1016/S0142-9612(97)00207-X

[11] Silver JH, Hart AP, Williams EC, Cooper SL, Charef S, Labarre D, et al. Anticoagulant effects of sulphonated polyurethanes. Biomaterials 1992; 13: 339-44. http://dx.doi.org/10.1016/0142-9612(92)90037-O

[12] Meddahi A, Benoit J, Ayoub N, Sézeur A, Barritault D. Heparin-like polymers derived from dextran enhance colonic anastomosis resistance to leakage. J Biomed Mater Res 1996; 31: 293-7.

http://dx.doi.org/10.1002/(SICI)10974636(199607)31:3<293::AID-JBM1>3.0.CO;2-H

[13] Meddahi A, Alexakis C, Papy D, Caruelle JP, Barritault D. Heparin-like polymer improved healing of gastric and colic ulceration. J Biomed Mater Res 2002; 60: 497-501. http://dx.doi.org/10.1002/jbm.1293

[14] Baumann R, Rys P. Metachromatic activity of $\beta$-cyclodextrin sulfates as heparin mimics. Int J Biol Macromol 1999; 24: 158.

\section{http://dx.doi.org/10.1016/S0141-8130(98)00058-0}

[15] Bentolila A, Vlodavsky I, Haloun C, Domb AJ. Synthesis and heparin-like biological activity of amino acid-based polymers. Polym Adv Technol 2000; 11: 377-87.

http://dx.doi.org/10.1002/10991581(200008/12)11:8/12<377::AID-PAT985>3.0.CO;2-D

[16] de Paz JL, Angulo J, Lassaletta JM, Nieto PM, Redondo-Horcajo M, Lozano RM, et al. The activation of fibroblast growth factors by heparin: synthesis, structure, and biological activity of heparin-like oligosaccharides. ChemBioChem 2001; 2: 673-85.

http://dx.doi.org/10.1002/1439-7633(20010903)2:9<673::AIDCBIC673>3.0.CO;2-7
[17] Ojeda R, de Paz J-L, Martín-Lomas M. Synthesis of heparinlike oligosaccharides on a soluble polymer support. Chem Commun 2003; 2486-7. http://dx.doi.org/10.1039/b307259b

[18] Polat T, Wong C-H. Anomeric reactivity-based one-pot synthesis of heparin-like oligosaccharides. J Am Chem Soc 2007; 129: 12795-800.

http://dx.doi.org/10.1021/ja073098r

[19] Hansen SU, Miller GJ, Cole C, Rushton G, Avizienyte E, Jayson GC, et al. Tetrasaccharide iteration synthesis of a heparin-like dodecasaccharide and radiolabelling for in vivo tissue distribution studies. Nat Commun 2013; 4.

[20] Miller GJ, Hansen SU, Avizienyte E, Rushton G, Cole C, Jayson GC, et al. Efficient chemical synthesis of heparin-like octa-, deca-and dodecasaccharides and inhibition of FGF2and VEGF 165-mediated endothelial cell functions. Chem Sci 2013; 4: 3218-22. http://dx.doi.org/10.1039/c3sc51217g

[21] Pereira MS, Mulloy B, Mourão PA. Structure and anticoagulant activity of sulfated fucans comparison between the regular, repetitive, and linear fucans from echinoderms with the more heterogeneous and branched polymers from brown algae. J Biol Chem 1999; 274: 7656-67.

http://dx.doi.org/10.1074/jbc.274.12.7656

[22] Andrade GP, Lima MA, de Souza Junior AA, Fareed J, Hoppensteadt DA, Santos EA, et al. A heparin-like compound isolated from a marine crab rich in glucuronic acid 2-O-sulfate presents low anticoagulant activity. Carbohydr Polym 2013; 94: 647-54 http://dx.doi.org/10.1016/j.carbpol.2013.01.069

[23] Yang J, Cai J, Wu K, Li D, Hu Y, Li G, et al. Preparation, characterization and anticoagulant activity in vitro of heparinlike 6-carboxylchitin derivative. Int J Biol Macromol 2012; 50: 1158-64.

http://dx.doi.org/10.1016/j.ijbiomac.2012.01.007

[24] Xue JM, Zhao WF, Nie SQ, Sun SD, Zhao CS. Blood compatibility of polyethersulfone membrane by blending a sulfated derivative of chitosan. Carbohydr Polym 2013; 95: 64-71.

\section{http://dx.doi.org/10.1016/j.carbpol.2013.02.033}

[25] Cen L, Neoh KG, Li Y, Kang ET. Assessment of in vitro bioactivity of hyaluronic acid and sulfated hyaluronic acid functionalized electroactive polymer. Biomacromolecules 2004; 5: 2238-46.

http://dx.doi.org/10.1021/bm040048v

[26] Brito AS, Arimatéia DS, Souza LR, Lima MA, Santos VO Medeiros VP, et al. Anti-inflammatory properties of a heparinlike glycosaminoglycan with reduced anti-coagulant activity isolated from a marine shrimp. Bioorg Med Chem 2008; 16: 9588-95.

http://dx.doi.org/10.1016/j.bmc.2008.09.020

[27] Charef $S$, Tapon-Bretaudière $J$, Fischer A-M, Pflüger $F$, Jozefowicz M, Labarre D. Heparin-like functionalized polymer surfaces: discrimination between catalytic and adsorption processes during the course of thrombin inhibition. Biomaterials 1996; 17: 903-12. http://dx.doi.org/10.1016/0142-9612(96)83286-8

[28] Jang HS, Ryu KE, Ahn WS, Chun HJ, Dal Park H, Park KD et al. Complement activation by sulfonated poly (ethylene glycol)-acrylate copolymers through alternative pathway. Colloids Surf, B 2006; 50: 141-6. http://dx.doi.org/10.1016/j.colsurfb.2006.03.024

[29] Ran F, Nie SQ, Li J, Su BH, Sun SD, Zhao CS. Heparin-like macromolecules for the modification of anticoagulant biomaterials. Macromol Biosci 2012; 12: 116-25. http://dx.doi.org/10.1002/mabi.201100249

[30] Blanco J-F, Sublet J, Nguyen QT, Schaetzel P. Formation and morphology studies of different polysulfones-based 
membranes made by wet phase inversion process. J Membr Sci 2006; 283: 27-37.

http://dx.doi.org/10.1016/j.memsci.2006.06.011

[31] lojoiu C, Maréchal M, Chabert F, Sanchez JY. Mastering sulfonation of aromatic polysulfones: crucial for membranes for fuel cell application. Fuel Cells 2005; 5: 344-54. http://dx.doi.org/10.1002/fuce.200400082

[32] Dyck A, Fritsch D, Nunes S. Proton-conductive membranes of sulfonated polyphenylsulfone. J Appl Polym Sci 2002; 86: 2820-7.

http://dx.doi.org/10.1002/app.11264

[33] Nolte R, Ledjeff K, Bauer M, Mülhaupt R. Partially sulfonated poly (arylene ether sulfone)-A versatile proton conducting membrane material for modern energy conversion technologies. J Membr Sci 1993; 83: 211-20. http://dx.doi.org/10.1016/0376-7388(93)85268-2

[34] Baradie B, Poinsignon C, Sanchez J, Piffard Y, Vitter G, Bestaoui $\mathrm{N}$, et al. Thermostable ionomeric filled membrane for $\mathrm{H}_{2} \mathrm{O}_{2}$ fuel cell. J Power Sources 1998; 74: 8-16. http://dx.doi.org/10.1016/S0378-7753(97)02816-4

[35] Pedicini R, Carbone A, Sacca A, Gatto I, Di Marco G, Passalacqua E. Sulphonated polysulphone membranes for medium temperature in polymer electrolyte fuel cells (PEFC). Polym Test 2008; 27: 248-59.

http://dx.doi.org/10.1016/j.polymertesting.2007.11.002

[36] Lufrano F, Baglio V, Staiti P, Arico AS, Antonucci V. Development and characterization of sulfonated polysulfone membranes for direct methanol fuel cells. Desalination 2006; 199: 283-5.

http://dx.doi.org/10.1016/j.desal.2006.03.069

[37] Lufrano F, Baglio V, Staiti P, Arico A, Antonucci V. Polymer electrolytes based on sulfonated polysulfone for direct methanol fuel cells. J Power Sources 2008; 179: 34-41. http://dx.doi.org/10.1016/j.jpowsour.2007.12.079

[38] Sanchez J-Y, Chabert F, lojoiu C, Salomon J, El Kissi N, Piffard $Y$, et al. Extrusion: An environmentally friendly process for PEMFC membrane elaboration. Electrochim Acta 2007; 53: 1584-95.

http://dx.doi.org/10.1016/j.electacta.2007.04.022

[39] Blanco J, Nguyen Q, Schaetzel P. Novel hydrophilic membrane materials: sulfonated polyethersulfone Cardo. J Membr Sci 2001; 186: 267-79. http://dx.doi.org/10.1016/S0376-7388(01)00331-3

[40] Unveren EE, Erdogan T, Çelebi SS, Inan TY. Role of postsulfonation of poly (ether ether sulfone) in proton conductivity and chemical stability of its proton exchange membranes for fuel cell. Int J Hydrogen Energy 2010; 35: 3736-44. http://dx.doi.org/10.1016/j.ijhydene.2010.01.041

[41] Lu D, Zou H, Guan R, Dai H, Lu L. Sulfonation of polyethersulfone by chlorosulfonic acid. Polym Bull 2005; 54 : 21-8. http://dx.doi.org/10.1007/s00289-005-0361-x

[42] Guan R, Zou H, Lu D, Gong C, Liu Y. Polyethersulfone sulfonated by chlorosulfonic acid and its membrane characteristics. Eur Polym J 2005; 41: 1554-60.

http://dx.doi.org/10.1016/j.eurpolymj.2005.01.018

[43] Guan R, Dai H, Li C, Liu J, Xu J. Effect of casting solvent on the morphology and performance of sulfonated polyethersulfone membranes. J Membr Sci 2006; 277: 148-56. http://dx.doi.org/10.1016/j.memsci.2005.10.025

[44] Li Y, Chung TS. Highly selective sulfonated polyethersulfone (SPES)-based membranes with transition metal counterions for hydrogen recovery and natural gas separation. J Membr Sci 2008; 308: 128-35. http://dx.doi.org/10.1016/j.memsci.2007.09.053

[45] Linares A, Benavente R. Effect of sulfonation on thermal, mechanical, and electrical properties of blends based on polysulfones. Polym J 2009; 41: 407-15.

http://dx.doi.org/10.1295/polymj.PJ2008252
[46] Bae T-H, Kim I-C, Tak T-M. Preparation and characterization of fouling-resistant $\mathrm{TiO}_{2}$ self-assembled nanocomposite membranes. J Membr Sci 2006; 275: 1-5. http://dx.doi.org/10.1016/i.memsci.2006.01.023

[47] Sangaj N, Kyriakakis P, Yang D, Chang C-W, Arya G Varghese S. Heparin mimicking polymer promotes myogenic differentiation of muscle progenitor cells. Biomacromolecules 2010; 11: 3294-300.

http://dx.doi.org/10.1021/bm101041f

[48] Nguyen TH, Kim S-H, Decker CG, Wong DY, Loo JA, Maynard HD. A heparin-mimicking polymer conjugate stabilizes basic fibroblast growth factor. Nat Chem 2013; 5: 221-7.

http://dx.doi.org/10.1038/nchem.1573

[49] García-Fernández L, Aguilar MaR, Fernández MaM, Lozano RM, Giménez G, Román JS. Antimitogenic polymer drugs based on AMPS: monomer distribution- bioactivity relationship of water-soluble macromolecules Biomacromolecules 2010; 11: 626-34. http://dx.doi.org/10.1021/bm901194e

[50] Wang LR, Qin H, Nie SQ, Sun SD, Ran F, Zhao CS. Direct synthesis of heparin-like poly (ether sulfone) polymer and its blood compatibility. Acta Biomater 2013; 9: 8851-63.

http://dx.doi.org/10.1016/j.actbio.2013.07.010

[51] Uchman M, Stepanek M, Procházka K, Mountrichas G Pispas S, Voets IK, et al. Multicompartment nanoparticles formed by a heparin-mimicking block terpolymer in aqueous solutions. Macromolecules 2009; 42: 5605-13. http://dx.doi.org/10.1021/ma9008115

[52] Zhou H, Cheng C, Qin H, Ma L, He C, Nie S, et al. Selfassembled 3D biocompatible and bioactive layer at the macro-interface via graphene-based supermolecules. Polym Sci 2014; 5: 3563-75.

[53] Li LL, Cheng C, Xiang T, Tang M, Zhao WF, Sun SD, et al. Modification of polyethersulfone hemodialysis membrane by blending citric acid grafted polyurethane and its anticoagulant activity. J Membr Sci 2012; 405-406: 261-74.

http://dx.doi.org/10.1016/j.memsci.2012.03.015

[54] Nie SQ, Xue JM, Lu Y, Liu YQ, Wang DS, Sun SD, et al. Improved blood compatibility of polyethersulfone membrane with a hydrophilic and anionic surface. Colloids Surf, B 2012; 100: 116-25.

http://dx.doi.org/10.1016/j.colsurfb.2012.05.004

[55] Ran F, Nie SQ, Yin ZH, Li J, Su BH, Sun SD, et al. Synthesized negatively charged macromolecules (NCMs) for the surface modification of anticoagulant membrane biomaterials. Int J Biol Macromol 2013; 55: 269-75. http://dx.doi.org/10.1016/j.ijbiomac.2013.01.014

[56] He C, Nie CX, Zhao WF, Ma L, Xiang T, Cheng CS, et al. Modification of polyethersulfone membranes using terpolymers engineered and integrated antifouling and anticoagulant properties. Polym Adv Technol 2013; 24: 104050.

http://dx.doi.org/10.1002/pat.3179

[57] Wang H, Yang L, Zhao X, Yu T, Du Q. Improvement of hydrophilicity and blood compatibility on polyethersulfone membrane by blending sulfonated polyethersulfone. Chin J Chem Eng 2009; 17: 324-9.

http://dx.doi.org/10.1016/S1004-9541(08)60211-6

[58] Tang M, Xue JM, Yan KL, Xiang T, Sun SD, Zhao CS. Heparin-like surface modification of polyethersulfone membrane and its biocompatibility. J Colloid Interface Sci 2012; 386: 428-40. http://dx.doi.org/10.1016/j.jcis.2012.07.076

[59] Nie SQ, Tang M, Yin ZH, Wang LR, Sun SD, Zhao CS. Biologically inspired membrane design with a heparin-like interface: prolonged blood coagulation, inhibited complement activation, and bio-artificial liver related cell proliferation. Biomater Sci 2014; 2: 98-109.

http://dx.doi.org/10.1039/c3bm60165j 
[60] Zhao WF, Mou QB, Zhang XX, Shi JY, Sun SD, Zhao CS. Preparation and characterization of sulfonated polyethersulfone membranes by a facile approach. Eur Polym J 2013; 49: 738-51.

http://dx.doi.org/10.1016/j.eurpolymj.2012.11.018

[61] Xiang T, Wang LR, Ma L, Han ZY, Wang R, Cheng C, et al. From commodity polymers to functional polymers. Sci Rep 2014; 4: 4604. http://dx.doi.org/10.1038/srep04604

[62] Qin H, Sun CC, He C, Wang DS, Cheng C, Nie SQ, et al. High efficient protocol for the modification of polyethersulfone membranes with anticoagulant and antifouling properties via in situ cross-linked copolymerization. J Membr Sci 2014; 468: 172-83. http://dx.doi.org/10.1016/j.memsci.2014.06.006

[63] Ma L, Qin H, Cheng C, Xia Y, He C, Nie C, et al. Musselinspired self-coating at macro-interface with improved biocompatibility and bioactivity via dopamine grafted heparinlike polymers and heparin. J Mater Chem, B 2014; 2: 363-75. http://dx.doi.org/10.1039/c3tb21388a

[64] Aravind UK, Mathew J, Aravindakumar C. Transport studies of BSA, lysozyme and ovalbumin through chitosan/polystyrene sulfonate multilayer membrane. J Membr Sci 2007; 299: 146-55. http://dx.doi.org/10.1016/j.memsci.2007.04.036

[65] Malaisamy R, Bruening ML. High-flux nanofiltration membranes prepared by adsorption of multilayer polyelectrolyte membranes on polymeric supports. Langmuir 2005; 21: 10587-92.

http://dx.doi.org/10.1021/la051669s
[66] Xia $\mathrm{Y}$, Cheng $\mathrm{C}$, Wang $\mathrm{R}$, Qin $\mathrm{H}$, Zhang $\mathrm{Y}, \mathrm{Ma} \mathrm{L}$, et al. Surface-engineered nanogel assemblies with integrated blood compatibility, cell proliferation and antibacterial property: towards multifunctional biomedical membranes. Polym Sci 2014. http://dx.doi.org/10.1039/C4PY00870G

[67] Taniguchi M, Belfort G. Low protein fouling synthetic membranes by UV-assisted surface grafting modification: varying monomer type. J Membr Sci 2004; 231: 147-57. http://dx.doi.org/10.1016/j.memsci.2003.11.013

[68] Taniguchi M, Kilduff JE, Belfort G. Low fouling synthetic membranes by UV-assisted graft polymerization: monomer selection to mitigate fouling by natural organic matter. J Membr Sci 2003; 222: 59-70. http://dx.doi.org/10.1016/S0376-7388(03)00192-3

[69] Zhao CS, Liu XD, Rikimaru S, Nomizu M, Nishi N. Surface characterization of polysulfone membranes modified by DNA immobilization. J Membr Sci 2003; 214: 179-89. http://dx.doi.org/10.1016/S0376-7388(02)00524-0

[70] Xiang T, Wang R, Zhao WF, Zhao CS. Covalent deposition of zwitterionic polymer and citric acid by click chemistryenabled layer-by-layer assembly for improving the blood compatibility of polysulfone membrane. Langmuir 2014; 30 : 5115-25. http://dx.doi.org/10.1021/la5001705

[71] Xiang T, Zhang LS, Wang R, Xia Y, Su BH, Zhao CS. Blood compatibility comparison for polysulfone membranes modified by grafting block and random zwitterionic copolymers via surface-initiated ATRP. J Colloid Interface Sci 2014; 432: 47-56. http://dx.doi.org/10.1016/j.jcis.2014.06.044 